Bulletin d'Histoire Contemporaine de l'Espagne

$51 \mid 2017$

Les forces politiques durant la Seconde République espagnole

\title{
La quiebra del socialismo en la segunda república
}

The failure of socialism in the Second Republic

La faillite du socialisme au cours de la Seconde République

José Manuel Macarro Vera

(2) OpenEdition

Journals

Edición electrónica

URL: http://journals.openedition.org/bhce/644

DOI: $10.4000 /$ bhce. 644

ISSN: 1968-3723

Editor

Presses Universitaires de Provence

Edición impresa

Fecha de publicación: 1 junio 2017

Paginación: 25-40

ISSN: 0987-4135

Referencia electrónica

José Manuel Macarro Vera, «La quiebra del socialismo en la segunda república », Bulletin d'Histoire Contemporaine de l'Espagne [En línea], 51 | 2017, Publicado el 09 octubre 2018, consultado el 19 abril 2019. URL : http://journals.openedition.org/bhce/644; DOI : 10.4000/bhce.644 


\section{La quiebra del socialismo en la Segunda República}

José Manuel MACARRO VERA

Universidad de Sevilla

$\mathrm{E}$ ntre los diversos puntos de vista que pueden seleccionarse para abordar un hecho histórico, cada vez estimo de la mayor importancia precisar bien los contornos de los sucesos o los sujetos que se va a analizar. Por no haberlo hecho en la historia de la II República española nos hemos metido en un mundo ideológico más que histórico. Digo esto porque entiendo por ideología una concepción abstracta de la realidad, que no la hace inteligible, porque sólo tiene validez en la esfera del pensamiento. Desde este presupuesto, mantengo que los hechos acaecidos durante la II República continúan presos de una concepción ideológica, hasta el punto que los debates académicos giran más sobre su apreciación que sobre los límites y características de los mismos en sí. Los ejemplos son numerosísimos. Puede ser uno de ellos la quema de iglesias en mayo de 1931. Si se repasan los manuales o los libros de síntesis, que son los que llegan a nuestros alumnos y al público, solemos leer que aquéllos se debieron a la provocación de unos monárquicos en Madrid. Con esto nos ahorramos explicar cómo un hecho tan minúsculo protagonizado por un exiguo grupo se extendió a otras ciudades. Tampoco sabemos hoy cuantas iglesias ardieron, ni tenemos medidas las reacciones de miedo de los católicos. En cambio sí conocemos, aunque lo silenciamos, el tremendo impacto que causaron los sucesos en el cuerpo diplomático acreditado en Madrid. Otro ejemplo, por el que me preguntaban mis alumnos, era por qué se ponen en plano de igualdad los asesinatos del teniente Castillo y de Calvo Sotelo. Uno más es seguir arguyendo, para justificar la ilegitimidad de la CEDA para formar Gobierno en 1934, que no había jurado la Constitución. También sorprendía a mis alumnos, como a cualquiera que haya consultado las proclamas, discursos y acción de las organizaciones políticas de la época, continuar diciendo que las de derechas eran antidemocráticas en contraste con el fervor democrático de las izquierdas. Por último, expondré un hecho más: el 31 de mayo de 1936, Indalecio Prieto, Juan Negrín y González Peña fueron tiroteados en Écija por miembros de las Juventudes Socialistas Unificadas. La Comisión Ejecutiva de la UGT, con Largo Caballero a la cabeza, se negó a condenar el atentado.

Estos meros ejemplos muestran la permanencia de la coartada ideológica para evitar detenernos en hechos, máxime si parecen incómodos. Porque ¿y si los incendios de mayo alcanzaron tal magnitud que acarrearon responsabilidades gubernamentales de enormes consecuencias para la República? Desde luego, los dantescos sucesos de Málaga, con su obispo refugiándose en Gibraltar, así lo indican. Pero ¿̇en cuántos libros sobre la República se hace referencia a ellos? ¿El mismo alcance tiene que unos pistoleros fascistas asesinen a un policía, que sean policías quienes hagan lo mismo con un muy importante diputado de derechas? ; Y vaya una novedad insistir en que la CEDA iba a modificar la Constitución! Esto lo anunció Acción Popular desde que se aprobó el que sería artículo 26 de ella, muchos 
días antes de la votación final de la misma. Por eso, en su programa en las elecciones de 1933, se comprometía a la reforma constitucional, pero nunca a anular la Constitución y menos a acabar con la República. Al silenciar esto último, nos evitamos tener que concluir que la derecha, por lo visto, no podía legalmente reformar la Constitución, por lo que estaba sobrando en el juego republicano por los siglos de los siglos. Por último, he de declarar que no entiendo por qué la mayor parte de la historiografía sigue ocultando el atentado realizado por socialistas contra Indalecio Prieto en Écija, que sólo veo citado en mis modestas publicaciones.

El error puede estar en no haber aquilatado los contornos de los hechos que historiamos, para seguir manteniendo una concepción ideológica de los mismos, abstracta por irreal. Cuántas veces nos seguimos encontrando alusiones constantes a la izquierda y la derecha, que meten en un mismo saco a sujetos tan distintos como los socialistas, los anarquistas, los anarcosindicalistas o los comunistas dentro de la primera, y a tradicionalistas, populares, monárquicos o falangistas dentro de la segunda. De esta manera, al reducir la variedad citada a dos sujetos únicos, se nos facilitan las explicaciones, porque siempre es más sencillo conjugar las acciones de dos sujetos que explicar las complejas interacciones de múltiples. Claro está que esto tiene un precio costoso: disolver los múltiples aspectos de la realidad, que son los que en verdad hay que entender, en aras de unificar nuestro relato, como se dice ahora. Con ello seguimos haciendo un flaco favor a nuestras explicaciones de la historia, y también, me temo, a nuestro gremio de historiadores ${ }^{1}$.

Viene esto a cuento del título de este artículo ${ }^{2}$. Es cierto que el sustantivo engloba fundamentalmente-descartando matices residuales-a una única corriente política agrupada en el PSOE y la UGT. En cambio, a la hora de actuar políticamente, ambos sujetos, el partido y el sindicato, no siempre fueron uno, sino con mucha frecuencia dos. La división de sujetos dentro del concepto genérico del socialismo constituyó un hecho histórico de la República, real y determinante ${ }^{3}$. Real, porque PSOE y UGT, partido y sindicato, fueron las organizaciones más fuertes que, en principio, defendieron a la República. Determinante

1 Una de las reflexiones más brillante y profunda que conozco sobre la II República es la de F. DEL Rey Regullo, «Policies of Exclusion during the Second Repúblic: A View from de Grass Roots», en M. Álvarez Tardio y F. Del Rey Reguillo (eds.), The Spanish Second Republic Revisited. From Democratic Hopes to Civil War (1931-1936), Brighton, Portland, Toronto, Sussex Academic Press, 2012 , p.167-187. Esta obra acaba de ser publicada en español por los mismos autores con el título $E l$ laberinto republicano. La democracia española y sus enemigos (1931-1936), Madrid, RBA Libros, 2012. Los mismos calificativos merece la contribución de M. Álvarez Tardío, p. 1-8. Aunque desbordan el tema concreto de estas páginas, es de obligada referencia el capítulo de $\mathrm{S}$. G. PAYNE, «A Critical Overview of the Second Spanish Republic», y el riguroso y meditado de L. ARRANZ, "Could the Second Republic have become a Democracy?n

2 Como sucede cuando uno ha publicado varios títulos sobre un mismo tema, las reiteraciones, hasta textuales, son inevitables. Pido disculpas por ello al lector. En la obra citada se encuentra un capitulo mío, "The Socialists and Revolution", p. 40-57, en el que se exponen muchas de las cosas que escribo en las presentes páginas. Mi libro de referencia sobre el tema, que me sirve de sustento para cuanto digo -de referencia al menos para mí, porque me ayudó a ser catedrático-, es Socialismo, República y revolución en Andalucía, Sevilla, Universidad, 2000. En él se dan cuenta de las fuentes que uso, junto con una cita de mis publicaciones al respecto.

3 Sugerentes son los artículos de M. CABRERA, «Algo más que un tiempo digno de ser descifrado: la Segunda República», y M. Pérez Ledesma, "Los socialistas y la política española. Un recorrido y una síntesis", en J. Álvarez Junco, M. CABRera, (Eds.), La mirada del historiador. Un viaje por la obra de Santos Juliá. Madrid, Taurus, 2011. Hay que añadir el número monográfico coordinado por J. ANDRÉSGallego y R. Borrás, «II República. Historia y mito», en Nueva Revista. De política, cultura y arte, 2011 , en el que contribuyo con «La Reforma agraria en la II República». 
porque derivado de esto, la suerte de la República en buena parte corrió pareja a la evolución del sujeto que denominamos «el socialismo». Entender los entresijos de éste actor en sus dimensiones organizativa e ideológica es acercarnos a la realidad de uno de los actores primordiales de la historia republicana ${ }^{4}$. Pero, al contrario que en el comunismo, de quien hemos heredado a veces hasta la terminología, el sindicato no era la correa de transmisión del partido sino al revés. El partido estaba para ayudar a conseguir los objetivos que la UGT se había marcado y que ella no podía alcanzar por sí sola. Era así porque únicamente la UGT era «la clase obrera organizada», mientras que el PSOE se limitaba a ser «la organización socialista». Esto explica que Largo Caballero, en su toma de posesión como ministro de Trabajo, hablase no como miembro del PSOE, que era un partido del Gobierno, sino en nombre de la UGT, de la clase trabajadora, que venía, nada menos, que a organizar «a los funcionarios con ellos y contra los que se opongan».

Desde esta bicefalia, armoniosa por el momento, se ha de entender que, al proclamarse la República, los socialistas se hubieran dirigido a la opinión pública en nombre de «nuestras organizaciones obreras y socialistas». Ellos eran conscientes de que por el momento no podían ir a la «República social», que era su meta. Mientras ese momento llegaba, y siendo conscientes de la debilidad de los partidos republicanos, «la clase obrera organizada será el más firme sostén del régimen republicano» para «que la República tenga un contenido social, un fondo sustantivo, sin el cual perdería su razón de ser». Fondo y contenido que tenía una medida precisa: El «fortalecimiento de nuestras organizaciones obreras y socialistas», ya que su participación gubernamental les permitiría ir «estructurándonos en sociedad de clase». Por si la cosa no estuviera diáfana, a los pocos días de la proclamación de la República, las ejecutivas de la UGT y el PSOE, declararon: «Esta República española que ahora empieza, y de la cual hemos de ser nosotros guardianes y vigilantes, es algo esencialmente nuestro porque a nuestro calor ha nacido y a nuestro calor ha de afirmarse y perfeccionarse en el futuro. De la proporción en que nosotros influyamos en su destino depende la vitalidad que alcance la República».

El sentido patrimonial de la República que contenían estas afirmaciones no admitía dudas. Ellas nos ayudarán a entender que un socialista moderado como Fernando de los Ríos afirmara que ellos pensaban mantener la democracia política para poder ir hacia una organización socialista de la economía. Prueba de ello, afirmó el periódico del PSOE, eran los decretos agrarios de mayo de Largo Caballero, que estaban estableciendo «el principio de la colectivización, en todos los sentidos, de España $»^{5}$. Y así debía ser, porque ellos reafirmaron de manera oficial que estaban en el Gobierno para ayudar a mantener a la República, pero además, y como requisito sine qua non, para afianzar las reformas que les llevasen al socialismo el día de mañana. Por eso exigieron que sus reformas quedaran consagradas en la Constitución, para que ningún otro Gobierno pudiera anularlas. Y de inmediato amenazaron a los republicanos: si no aceptaban esta exigencia, significaría que no había habido verdadera revolución; entonces tendrían que salir a la calle para hacerla.

¿Bravatas? Sí en cuanto los socialistas eran conscientes de su debilidad para hacer revolución alguna por su cuenta. A pesar de ser el partido y el sindicato más fuerte de España, todavía en mayo de 1931 estaban organizando sus federaciones regionales, que no tenían, y el gran sindicato agrario, la FNTT, estaba comenzando a constituirse desde

4 Sobre los socialistas hay un texto de profundidad inhabitual, que casi hace ociosas estas páginas mías: el capítulo de F. Del Rey Regullo, «La República de los socialistas», en la obra dirigida por él Palabras como puños. La intransigencia politica en la Segunda República española», Madrid, Tecnos, 2011. 
la nada. Punto de vista éste que no debe olvidarse para entender la República: si el PSOE y la UGT tenían una estructura nacional extremadamente precaria en 1931, y eran las organizaciones más fuertes de España, el resto de partidos y sindicatos apenas eran nada desde el punto de vista organizativo. Afirmación que vale también para las cifras míticas e insostenibles de la CNT.

Pero no eran bravatas cuando se dirigieron a los republicanos en noviembre, recién aprobada la Constitución. Es conocido que éste fue el momento en que los republicanos radicales pretendieron que el PSOE abandonara el Gobierno ${ }^{6}$. La reacción socialista fue doble. Por un lado, Prieto y De los Ríos afirmaron que eso no era posible, porque los republicanos no les ofrecían garantías para «regir el destino de la República». Por si esta reiteración del sentido patrimonial de la República no bastase, Largo Caballero intervino para añadir que el PSOE y la UGT considerarían tal salida como una provocación, «que nos obligaría a ir a una guerra civil» $\rangle^{7}$.

El escándalo monumental que causaron las palabras de don Francisco, llevó a los socialistas a dulcificar piadosamente la amenaza como referencia a «una guerra civil espiritual». Pero en verdad la amenaza había sido bien terrenal. Lo era porque estaba enraizada en el significado que los socialistas otorgaban a la República y a la democracia misma. Para algunos, pocos, ambas eran bienes en sí mismos. Pero para la mayoría, según palabra de uno de sus líderes, cada una sólo era una «estación de tránsito» hacia el socialismo. Estación que únicamente sería válida si consolidaba, sin vuelta atrás posible, las posiciones que los socialistas hubieran conseguido en ella. De no ser así, si esas posiciones fueran limadas por alguien, los socialistas se considerarían desligados de cualquier compromiso con la República.

Esas posiciones quedaron establecidas de inmediato en los decretos agrarios de mayo de 1931, después convertidos en leyes. En mi opinión, estos fueron determinantes para la fidelidad socialista a la República. En primer lugar, estaba la muy conocida Ley de Términos Municipales, que daba preferencia a la colocación de los obreros de cada pueblo sobre los forasteros. La ley fue una catástrofe para el mercado de trabajo y ocasionó muchos disgustos a los socialistas, incluso entre sus afiliados, que la llamaron pronto «ley de fronteras». Los registros de los obreros se harían en los ayuntamientos, que serían los encargados de repartir el trabajo que hubiera. Otro decreto extendió los Jurados Mixtos a la agricultura. En los pueblos existirían comisiones de ellos con capacidad para interpretar sus acuerdos y la propia legislación laboral. Se crearon las Comisiones de Policía Rural, con potestad para decidir qué labores había que hacer en las tierras y con cuántos trabajadores; incluso tenían capacidad para entregar las tierras que considerasen mal labradas a los sindicatos, mediante la ley de Intensificación de Cultivos. Intensificación llevada a cabo en suficientes ocasiones, para hacernos ver que la mejor o peor labranza de las tierras era un tema accesorio a la hora de decidirla, pues la ocupación y entrega de las tierras a la UGT se hacía para dar trabajo a los parados. Después, la cruda realidad vino a mostrar -al menos en los casos que se van conociendo- que con las parcelas que se entregaban no había jornalero que pudiera vivir.

Estos organismos estaban presididos por alcalde, que en los pueblos socialistas solía ser el presidente de la Casa del Pueblo, mientras que los vocales obreros eran miembros de

6 Sobre Martínez Barrio y los radicales, la magna obra de L. Álvarez Rey, Diego Martinez Barrio. Palabra de republicano. Sevilla, Ayuntamiento, 2007.

7 El Socialista, 24-11-1931. 
la FNTT. A estos organismos se añadieron los Jurados Mixtos de la Propiedad Rústica, competentes en los contratos de arrendamiento, y presididos por el juez de instrucción cuando lo hubiera; en su defecto, la presidencia recaería en el juez de paz elegido por los vecinos, normalmente un socialista en los pueblos dominados por éstos. Y hubo más: los Delegados de Trabajo, nombrados por el ministerio de Largo Caballero, tenían competencia exclusiva en los conflictos laborales, incluidos los que les elevaran desde los pueblos. Únicamente en los casos en que esos delegados no existieran, podrían intervenir los alcaldes y los gobernadores. Por si fuera poco, los socialistas exigieron que los representantes de los trabajadores en los órganos de arbitraje pertenecieran a sindicatos genuinamente obreros, eufemismo para reservar la representación a la UGT -dado que la CNT se autoexcluía por definición-e impedir la de los republicanos.

La consecuencia era palmaria: los socialistas habían establecido un tejido que les daba el control de las relaciones laborales. Porque en los casos en que los alcaldes o los concejales republicanos fuesen mayoritarios en alguno de los organismos citados, siempre cabía la posibilidad de recurrir a las instancias superiores -bien fueran los Jurados Mixtos comarcales o provinciales, o los Delegados de Trabajo- para que modificaran los acuerdos ingratos para la UGT. De esta manera la política socialista quedó bien definida, a través de la UGT y FNTT como intérpretes y ejecutores de la legislación laboral, con capacidad de decidir, por ejemplo, qué labores agrarias había que realizar y con cuántas peonadas; con el poder de arbitraje concedido a las autoridades socialistas, que hasta podían interpretar la legislación social. De esta manera la UGT pasó a ser representante legal del Estado.

Los socialistas estaban exultantes. El fortalecimiento de sus organizaciones era síntoma de la salud republicana. Sus reformas laborales, controladas exclusivamente por ellos, se habían convertido en leyes para garantizar su irreversibilidad. Y si los débiles republicanos flaqueaban en algún momento, ahí estaban ellos, pues «los peligros que para la estabilidad de la República pudieran derivarse de la heterogénea composición del Gobierno están conjurados por la presencia en éste de los representantes del Partido Socialista».

En octubre de 1932, al año y medio de la proclamación de la República, el PSOE y la UGT realizaron sus respectivos congresos nacionales. En ellos ningún delegado propuso alguna medida de las denominadas revolucionarias, como nacionalizaciones o expropiaciones. Lo que todos querían era que se mantuviera la legislación social, excepto la odiada «ley de fronteras». Nadie parecía querer más, porque, como expuso Besteiro, cuanto habían conseguido era mucho más de lo que esperaban el 14 de abril, máxime cuando «no somos la mayoría ni en el Parlamento ni en el país». Prieto continuó la línea argumental: si ahora se le entregara el poder al PSOE, sería el suicidio del partido, porque España no estaba preparada para el socialismo. Y en medio del entusiasmo de los congresistas, agregó: como los republicanos eran incapaces de consolidar la República, a los socialistas les correspondía hacerlo por el camino que venían siguiendo, llenándola de contenido social. Contenido intrínsecamente anudado a la permanencia socialista en los organismos de control laboral, que era donde se estaba consolidando la clase obrera consciente, es decir, la UGT, para que la estación de tránsito republicana nunca tuviera marcha atrás. Por ello proclamó Largo Caballero: «Y desgraciados de nosotros el día que abandonemos esos puestos».

Eso nunca podría ser. Si los republicanos lo olvidaban, y volvía a insinuar alguno de ellos otra vez que los socialistas tenían que abandonar el Gobierno; de suceder lo considerarían un golpe de Estado, por lo que se reservarían el derecho de recurrir a la violencia.

Esta nueva amenaza, efectuada por las ejecutivas de la UGT y el PSOE, era similar a la antes citada de Largo Caballero, y ninguna se hizo a humo de pajas. Vinieron a cuento 
porque las medidas agrarias socialistas estaban poniendo en pie de guerra al mundo del campo. Y en contra del tópico permanente, no fueron los grandes terratenientes los primeros en iniciarla, sino los medianos y pequeños agricultores. La denuncia constante desde el invierno de 1931 fue que los socialistas eran unos tiranos que los estaban arruinando mediante la imposición de unas bases de trabajo leoninas a través de los organismos de arbitraje. Por si no bastara esta protesta, los jornaleros de los pueblos de las sierras estaban casi en pie de guerra, porque la Ley de Términos los tenía sitiados en sus paupérrimos pueblos, sin dejarles bajar a las campiñas durante las recolecciones, como lo habían hecho toda la vida. La situación se iba encrespando día a día, hasta llegar a ser explosiva como pasó en Jaén, en el momento en que los Delegados de Trabajo o los presidentes de los Jurados Mixtos, a la hora de arbitrar algún conflicto determinante, llegaron a votar en contra de la propuesta que ellos mismos habían formulado, al ver que sus compañeros de la UGT la rechazaban ${ }^{8}$.

Otro tópico vigente hasta hoy es el que encierra la famosa frase «que os dé de comer la República». La frase se pudo pronunciar, sin duda, pero no porque los propietarios decidieran dejar de labrar sus fincas para arrinconar por el hambre a los jornaleros. Esto hubiera supuesto una conciencia y fortaleza de clase desconocida en la historia: la de preferir arruinarse con tal de acabar con los enemigos de clase, como un nuevo Sansón que gritara «muera yo y conmigo todos los filisteos». Los propietarios esgrimieron la frase cuando se encontraron con que no podían pagar los salarios impuestos por las bases de trabajo aprobadas por los Jurados Mixtos. Esto había sucedido pronto en Jaén, en 1931, como admitieron los socialistas, y como venía pasando en otros muchos pueblos según lo reconocieron los diputados del PSOE en las Cortes en 1932. Este reconocimiento en las Cortes merece ser rememorado, pues cuando se argumentó en ellas que las bases de trabajo estaban arruinando a la economía agraria, los portavoces socialistas reconocieron que era cierto, pero que la responsabilidad de que sucediera así no era de ellos ni de la FNTT sino del capitalismo9. La cadena de sinsentido culminó en 1933 en Sevilla, cuando la Federación Socialista tuvo que pedir al Gobierno que arbitrase préstamos para los grandes terratenientes, pues reconocía que se habían quedado sin dinero para pagar los salarios de la recolección. Realidad ésta que, por mucho que la documentemos en nuestras publicaciones, sigue descansando en el limbo de la historiografía políticamente correcta, incomprensiblemente denominada progresista.

Como he escrito en otro lugar, con estos mimbres es fácil entender por qué en 1933 la reacción contra los socialistas llegó a ser tremenda, y no sólo por parte de la derecha y de los republicanos radicales, sino por quienes resultaron determinantes en la ofensiva: los

8 El desarrollo de los acontecimientos en «M. Barrios. Delegado Regional de Trabajo en Andalucía», El Socialista, 3-1-1932; El Sol, 8 y 30-1-1932; Diario de Sesiones de Cortes, 2-2-1932, p. 3544.

9 A mediados de noviembre de 1931 el Gobernador Civil de Sevilla pronunció una conferencia en la que atacó a los socialistas. En los inicios de 1932 se publicó de manera más detallada como informe mandado al Gobierno, que contenía un ataque demoledor a la política agraria de los socialistas. Se acusaba a ésta de ser la responsable de la ruina de los agricultores y, por tanto del aumento del paro. En él se desmentía de forma rotunda que los propietarios hubieran dejado de cultivar sus tierras. En El Liberal y $A B C$, ambos de Sevilla, 12-1-1932. La respuesta socialista, con el cometario añadido de que el responsable era el capitalismo, en «Los diputados socialistas contestan al Gobernador de Sevilla», El Socialista, 20-111931. Una ampliación de la cuestión se encuentra en un debate esencial sobre el tema agrario realizado en las Cortes, en Diario de Sesiones, 18-10-1932, p. 8924-8927; 19-10-1932, p. 8963; 20-10-1932, p. 9007-9052. En él los diputados del PSOE fueron incapaces de responder a las razones económicas que esgrimieron los de la oposición. Fue García Valdecasas, miembro entonces de la Agrupación al Servicio de la República, el que hizo la pregunta de si no había economistas en el PSOE. 
republicanos de izquierdas ${ }^{10}$. Las acusaciones por parte de todos fueron inmisericordes: los tildaron de tiranos, de incultos, de sectarios, de implantar la dictadura en el campo, de estar arruinando al país, de apropiarse de la República haciéndola socialista... ${ }^{11}$

La respuesta de muchos socialistas fue sorprendente. Así la de los diputados por Granada, quienes proclamaron: «contra la dictadura burguesa, la dictadura socialista». Para más inri, estos diputados pertenecían al sector moderado del partido. Otros consideraron que salir del Gobierno sería dejar avanzar al fascismo; más aún: sólo el hecho de abandonarlo ya sería «en el fondo, fascista»(sic). Cuando Fernando de los Ríos mostró su malestar por estas «contaminaciones terribles» que veía en el partido, la contestación de sus compañeros fue que tenía agotado «el sentido humanista del socialismo». Algunos más añadieron: nosotros respetaremos la democracia burguesa mientras ésta no entorpezea nuestro camino. Besteiro, muy preocupado por lo que escuchaba, se enfrentó a la deriva de sus correligionarios. Les advirtió que no podían confundir a Marx con Lenin. Por eso no tenían derecho a amenazar a la República porque pudieran salir de su Gobierno. Un testigo del momento, como muchos otros, evidenció el contrasentido, y escribió: amenazaban al Gobierno con la revolución con el fin de seguir formando parte de él.

Y resultó que, en septiembre de 1933, se encontraron fuera del mismo. Los socialistas quedaron conmocionados. Tanto que, al reunirse a los pocos días el Comité Nacional del PSOE, empezaron a entreabrir la caja de los truenos. Sorpresivamente varios delegados propusieron organizarse para tomar el poder. Decimos sorpresivamente porque antes todos los delegados informaron que no eran mayoría en ninguna región de España. Como muestra definitiva del desconcierto que provocó en el PSOE su salida del Gobierno, aprobaron manifestar su decisión de defender la República de los reaccionarios y, al mismo tiempo, la necesidad de conquistar el poder político para implantar el socialismo. Las dos cosas vinieron adobadas por expresiones como «la palabra democracia está en desuso», «nuestra democracia es distinta a la burguesa», o «los postulados socialistas son diferentes de los republicanos y los democráticos».

La identificación socialista con la República se quebraba. La pérdida del poder había puesto en tela de juicio que la República fuese ese régimen «esencialmente nuestro», el mismo que gracias a la participación en el Gobierno les permitía «estructurarnos en sociedad de clases». Eso se les había venido abajo. Aunque todavía les quedaba una trinchera que defender, aquella que señalaron en los inicios republicanos, cuando establecieron que la salud republicana vendría medida por la fortaleza de «nuestras organizaciones obreras y socialistas», y la que había postulado que nunca estarían dispuestos a permitir que nadie corrigiesen sus leyes sociales ni el control que tenía la clase obrera -es decir, la UGT- de los organismos de arbitraje. Precisamente contra ambas cosas se había levantado la ola antisocialista, hasta el punto de que todos los partidos habían llevado en sus programas electorales la necesidad de anularlas, o modificarlas sustancialmente, para acabar con la tiranía socialista.

Al triunfar la CEDA en las elecciones del 19 de noviembre de 1933, los socialistas quedaron aturdidos. Hasta el día 23 no reaccionaron. Cuando lo hicieron fue para decir que las elecciones habían sido fraudulentas, que el régimen había fracasado y estaban como

10 Para las izquierdas republicanas remito al enjundioso libro de J. AvIÉs, La izquierda burguesa y la tragedia de la II República. Madrid, Servicio de Documentación de la Comunidad Autónoma, 2006.

11 El apoyo documental de estas descalificaciones se encuentra en las p. 170-189, dentro de los epígrafes "La unión de las ofensivas» y "La marea antisocialista» de mi libro citado Socialismo, República y revolución en Andalucia. 
antes del 12 de abril de 1931. Prieto oficializó el órdago: si se entregaba el poder a los reaccionarios, «el pueblo español estará en el deber de levantarse revolucionariamente».

El 25 de noviembre se reunieron las ejecutivas del PSOE y de la UGT para aquilatar la necesidad de organizar alguna acción para impedir, en palabras de Largo Caballero, «una cosa de tipo fascista». Besteiro, con el apoyo de los dirigentes que controlaban a la UGT, volvió a enfrentarse con la corriente que empezaba a ser mayoritaria. Él pensaba que si había que ir a algún movimiento tenía que ser para defender la democracia y la República. Desde luego, promover una sublevación de carácter socialista era un disparate por varios motivos. El primero, porque era una incoherencia reconocer que eran una minoría en España y, al mismo tiempo, proponer un golpe de fuerza. El segundo, porque para hacer una revolución antes había que acabar con la democracia interna en el partido y el sindicato; esto acarrearía convertir a ambos en organizaciones como las comunistas, que eran la negación del socialismo. El tercero, porque los resultados electorales no se habían producido por un rechazo de la República y de la democracia, sino de la permanencia de los socialistas en el poder. Por todo, lo que había que hacer era esperar a ver qué política seguía el Gobierno y, desde luego, abandonar de inmediato la acusación ridícula, que no se creía nadie, de que Lerroux representaba al fascismo.

La lógica que contenía esta reflexión de Besteiro - algo más sólida que «la cosa de tipo fascista» caballerista- sólo tenía una salida política desde el punto de vista interno de la organización: o el PSOE la aceptaba y, consecuentemente, frenaban su discurso insurreccional, o tenía que anular políticamente a D. Julián, que es lo que quería Largo Caballero, confesadamente harto de él. La batalla se inició de inmediato, pues aunque el acuerdo de compromiso de las ejecutivas se limitó a anunciar que estaban alerta ante cualquier desvirtuación de la República, el periódico oficial venía llamando constantemente a tomar el poder. Ante la deriva de la situación, los besteiristas de la UGT pidieron insistentemente que se convocara un congreso que aclarara la línea política a seguir. Pretensión a la que Largo Caballero se oponía. Él, como buen ugetista, sabía que la organización socialista de masas, la que proporcionaba músculo político al PSOE, era la UGT. Como ésta estaba controlada por los seguidores de Besteiro, si se reunía su congreso éstos marcarían la política a seguir. Entonces la ejecutiva del PSOE inició una campaña para ir controlando las diversas federaciones de la UGT, sin tener que recurrir al congreso nacional que ésta exigía. En enero de 1934 las controlaban todas menos la de los ferroviarios. El grupo de Besteiro, en manifiesta minoría, hubo de dimitir. El partido y el sindicato ya estaban controlados por la gente de Largo Caballero, que en este momento contaba con el apoyo de la mayoría de los socialistas.

A Besteiro sólo le quedó hacer una durísima advertencia a los vencedores. Esos compañeros, dijo, estaban llevando las organizaciones «a los molinos del comunismo». «Por ese camino de locuras decimos a la clase trabajadora que se la lleva al desastre, a la ruina y en último caso se la lleva al deshonor, porque una clase trabajadora que se deja embaucar de esta manera $[\ldots]$ acaba de deshonrarse $\rangle^{12}$.

Tan durísima denuncia no parece que haya sido puesta de relieve como merece por la historiografía sobre la República. Y es necesario recalcarla, porque estaba denunciando en fecha tan temprana como 1933, que el amor por la República de la mayoría de sus

12 Toda la conmoción socialista tras perder las elecciones, con los debates subsiguientes, en Fundación Pablo Iglesias, AH-20-2, «Actas CE PSOE», 9-11 y 20-12-1933; 10-18-1-1934; "Actas CE UGT», 2411-1933; AH-24-1, «Actas CN PSOE», 26-11-1933. 
compañeros socialistas había sido sólo instrumental y, consecuentemente, insustancial el que pudieran haber tenido por la democracia. Prueba de esta afirmación es como descalificaron a la República, arguyendo que los republicanos de izquierda habían sido quienes comenzaron la campaña contra la legislación social y los ayuntamientos socialistas. Un régimen «donde cualquier majaderete» podía actuar así merecía una única respuesta: en el pasado fuimos republicanos, ahora sólo socialistas. Otros fueron más lejos al afirmar, «no somos republicanos, no lo hemos sido nunca. Somos socialistas. Sólo socialistas».

Los artículos de El Socialista eran incendiarios. «Queremos el Poder para nuestro Partido. Queremos la victoria para el Socialismo. Antes de ahora hemos avisado que nuestra obligación reside en no atarnos a la democracia y al parlamentarismo, obligación tanto más imperiosa cuanto la democracia y el parlamentarismo nos obstruyen el paso». Frente a las llamadas a la concordia que venía haciendo el diario de la derecha católica El Debate, el portavoz del PSOE respondió: «¿Concordia? No. ¡Guerra de clases! Odio a muerte a la burguesía criminal. ¿Concordia? Sí, pero entre los proletarios de todas las ideas que quieran salvarse y librar a España del ludibrio. Pase lo que pase, ¡atención al disco rojo! $\rangle^{13}$

Otra amenaza más ya la había formulado Prieto, al anunciar solemnemente en las Cortes que si la CEDA entraba en el Gobierno, «decimos desde aquí al país entero, que públicamente contrae el Partido Socialista el compromiso de desencadenar la revolución» ${ }^{14}$.

A partir de este momento, llovieron las denuncias de que en el campo estaban volviendo los salarios de hambre, cosa que era falsa ${ }^{15}$. La cuestión real no era ésta, sino que el Gobierno del Partido Radical estaba enmendando la legislación laboral socialista, como había prometido en la campaña electoral, y que había sido, como dijimos, el punto de unión de todos contra el PSOE. El Gobierno aducía que la mayoría de los conflictos en el campo se habían debido a una interpretación abusiva de la legislación por los Jurados Mixtos y las comisiones locales de los pueblos. La Ley de Términos Municipales había sido otro desastre, al enclaustrar en sus pueblos a jornaleros que desde siempre salían de ellos en las recolecciones. Acerca de la intensificación de cultivos se decía lo mismo: se habían ocupado tierras para repartir unas parcelas sin sentido, pues con su tamaño era imposible que viviera una familia. Respecto a los ayuntamientos era urgente quitarles competencias de orden público, porque habían demostrado que la norma de su actuación había sido la arbitrariedad, hasta el punto de que en muchas ocasiones habian sido los alcaldes los dirigentes de los conflictos.

Al debatirse en las Cortes todas estas rectificaciones legislativas, llama la atención que los socialistas sólo pudieran esgrimir a su favor meras generalidades, mientras eran acusados de ser los nuevos y verdaderos caciques, que habían acorralado a cuantos no eran socialistas. Lo único que pudieron decir fue que se diera más tiempo para estudiarlas. A la hora de rectificar el nombramiento de los presidentes de los Jurados Mixtos el debate fue muy significativo de la mentalidad de los socialistas. Hasta entonces, si no había acuerdo

13 «iAtención al disco rojo! No puede haber concordia», El Socialista, 3-1-1934. Las otras expresiones en el mismo diario, 5 y 6-12-1933, «Tenemos que adueñarnos del Poder» y «El momento clerical de España).

14 El Socialista, 21-12-1933.

15 A esta afirmación tan historiográficamente incorrecta le he dedicado un epígrafe, «El arma política de los atropellos», y un capítulo, «La tierra», en mi libro Socialismo, República y revolución en Andalucía, p. 319-330 y 191-229. La FETT, el poderoso sindicato agrario de la UGT, se había encargado de hacer una campaña denunciando la vuelta a los salarios de hambre. Pues bien, cuando se leen con detenimiento sus denuncias, se constata que siempre se refieren a unos minúsculos pueblos de Salamanca. Así en El Socialista, 13-5-1934 y El Obrero de la Tierra, 24-2, y 3, 24, 31-3-1934. 
entre las partes a la hora de designarlos, los nombraba el Ministerio de Trabajo. De aquí la oposición al sistema, porque para presidir los jurados determinantes se había nombrado a socialistas. Lo que ahora se proponía era que los presidentes fuesen funcionarios de alto nivel y que accediesen al puesto por concurso. Los socialistas se opusieron rotundamente porque, según ellos, un funcionario podía ser muy buen abogado o muy buen ingeniero, pero su cultura era libresca, tan alejada del mundo del trabajo que en él fracasaban de plano. Este tipo de lógica fue la misma que emplearon para que no hubiera ingenieros agrónomos en la aplicación de la Reforma Agraria, porque éstos se empeñaban en hacer estudios de la viabilidad económica de los asentamientos, y si esa viabilidad se metía por en medio pocos asentamientos se podrían hacer.

La mentalidad socialista se traslucía de lleno. Los representantes de la clase obrera no podían fiarse de los técnicos del Estado. El mundo del trabajo debía estar preservado de la contaminación de esa cultura libresca que tenían los altos funcionarios, y de las necesidades de la economía, que era la que limitaba los deseos de los trabajadores. En definitiva, estos trabajadores, los únicos que tenían un «íntimo conocimiento del mundo de trabajo», eran quienes debían prevalecer siempre sobre esos funcionarios, pertenecientes a otra clase social, y por lo mismo sobre el Estado que sustentaban. Más como la clase trabajadora en sí era algo amorfo, la responsabilidad recaía en la clase obrera organizada por excelencia: en la Unión General de Trabajadores de España ${ }^{16}$.

Al ver los socialistas que se les estaba viniendo abajo todo el control institucional de las relaciones laborales, los nuevos y jóvenes dirigentes del sindicato agrario de la UGT, la FETT, decidieron responder a lo que entendían que era un momento de confrontación, y en febrero de 1934 acordaron que harían una huelga general en la siega de mayo y junio. Entonces ninguno sabía cómo podía ser la cosecha ni que bases de trabajo estarían vigentes; ni siquiera arguyeron empeoramiento alguno de las condiciones de trabajo. La decisión de hacerla fue exclusivamente política.

En el proceso de su convocatoria y realización se puso de relieve la necesidad de entender el carácter del sujeto histórico, al que nos referimos al comienzo de estas páginas. Así vemos que al consultar la iniciativa con Largo Caballero, éste reaccionó como el líder sindical que esencialmente era. Les advirtió del peligro que estaban corriendo al llevar al sindicato a una aventura que podía destrozarlo. Si los jornaleros estaban tan mal como decían, lo oportuno era presentar las reclamaciones al grupo parlamentario socialista, para que éste las llevase al Gobierno para que interviniese. Finalmente les hizo una advertencia: si iban a la huelga, que no contasen con la UGT, porque a él no le volvían a destrozar los sindicatos como le sucedió en 1917.

Así eran las cosas en la práctica política de los socialistas al margen de los discursos revolucionarios. Los sindicatos, que tanto trabajo había costado formar, no podían ser arriesgados en una huelga azarosa porque, como dijeron en la ejecutiva de la UGT, una huelga general en el campo carecía de sentido en estas fechas, en febrero o marzo, porque los jornaleros estaban parados pues no era época de trabajo, y en las de la recolección porque ésta comenzaba en cada comarca en semanas distintas.

Los de la FETT hicieron oídos sordos y empezaron a preparar la huelga sin que la UGT pudiera impedirlo. No podía porque estatutariamente no tenía autoridad para hacerlo, pues sus federaciones sindicales eran autónomas, por lo que sus decisiones no podían

16 La información más jugosa al respecto se encuentra en Diario de Sesiones de Cortes, 7-2-1934, p. $942-$ 954; 23-3-1934, p. 1776-1783; 28-3-1934, p. 1962 
ser anuladas por la Comisión Ejecutiva de la UGT. E igual sucedía al PSOE, donde los dirigentes locales eran elegidos por los afiliados, que eran los que decidían quienes formarían las candidaturas en todas las elecciones. Y ambos con unos comités democráticamente constituidos por elección, que eran quienes decidían las estrategias politicas y los posibles conflictos internos. En el caso de que éstos últimos no pudieran solucionarse, se recurría a convocar los congresos nacionales. Por si fuera poco, en todos estos organismos se tomaban notas taquigráficas de los debates, que con frecuencias hasta se publicaban. Con esta organización los socialistas estaban preparados para actuar en una democracia, porque internamente funcionaban así, pero no para llevar a cabo una insurrección. Y mucho menos una revolución, porque éstas no se hacen con elecciones desde las bases, autonomía de los sindicatos, actas taquigráficas, contrapesos de poderes internos, luz y taquígrafos. Besteiro llevaba toda la razón: para hacer la revolución que estaban pregonando sus compañeros, antes había que acabar con la democracia interna dentro del partido y el sindicato, para transformar las organizaciones socialistas en comunistas. Pero Besteiro ya no pesaba nada dentro del socialismo, y quienes sí lo hacían no parece que se dieran cuenta de hacia dónde llevaba la deriva adoptada, al creer compatible el mantenimiento de una estructura interna democrática con un nuevo discurso revolucionario.

La campaña de propaganda que realizó la FETT para preparar la huelga es el primer ejemplo de esta esquizofrenia política. Por una parte fueron constantes los llamamientos a los campesinos para que tomaran el poder, para implantar la república social, una nueva república muy distinta a la de abril: «Así triunfan en Rusia, así triunfaremos nosotros», «iInsurrección armada, Revolución!» Por otra, resulta que en Córdoba se firmaron las bases de trabajo en el Jurado Mixto, y en Sevilla se prorrogaron las de 1933 en el mismo organismo, con gran satisfacción de los socialistas. Entonces, si en dos de las grandes provincias latifundistas no habría huelga, la general carecía de sentido. Para esquivar el escollo y pudiera haberla, el secretario de la FETT impugnó la prórroga de las bases de Sevilla. Ante el escándalo que se formó, el Ministro de Trabajo denunció que lo que existía era la intencionalidad política de hacer una huelga. Al verse desautorizada, la FETT recurrió a denunciar los salarios míseros que justificaban la huelga, que cuando se comprobaron resultó que eran siempre los de dos minúsculos pueblos de Salamanca.

El Ministerio ordenó que se aprobaran las bases por los Jurados Mixtos sin permitir la reducción de salarios, pero sin romper los equilibrios de la economía agraria, es decir, sin volver a la «ley de fronteras». La FETT, al ver que el sentido de la huelga se perdía por horas, cambió de golpe sus reivindicaciones. Ahora exigió que el trabajo se repartiera por un turno obligatorio bajo la supervisión exclusiva de la UGT, sin que el Estado pudiera intervenir. Ahí era nada: lo que los socialistas exigian era que el Estado desapareciera del campo, para regalarle el control de las relaciones laborales a ellos. Como es de suponer, el Gobierno se opuso.

La huelga se realizó y fue un fracaso. Entonces la UGT se dirigió al Gobierno para negociar con él una salida que salvara las bases de trabajo y minimizara las detenciones. Esta negociación incide en la esquizofrenia política a la que antes aludimos, pues revela el mantenimiento de una acción sindical tradicional y moderada con un discurso y propuestas incendiarias. $\mathrm{Al}$ añadirle la estructura autónoma y federal de sus sindicatos, todo se sumaba para que el socialismo español se descoyuntara ${ }^{17}$.

17 La preparación y desarrollo de la huelga campesina de 1934 está documentada en Fundación Pablo Iglesias, Actas CE-UGT, 1934 y Diario de Sesiones de Cortes, 30-5-1934. 
Esto se hizo realidad en octubre de 1934 a través de un camino disparatado. Ejemplo de ello fue Comité Nacional de la UGT de julio de 1934, en el que Largo Caballero le puso los puntos sobre las íes al delegado de la Federación de Trabajadores de la Enseñanza, un izquierdista próximo al PCE, tal como denunció don Francisco. El delegado criticó que la UGT no hubiera ido a la huelga en apoyo de los campesinos, como hubiera hecho Lenin. Largo Caballero sacó a la luz su responsabilidad sindical más tradicional y fue inmisericorde con el de la Enseñanza. Para empezar, le espetó que la UGT no seguía consignas ni de Lenin ni de nadie. A continuación le añadió que a Lenin quisiera haberlo visto aquí, con el proletariado español, o en Rusia sin los soldados que abandonaron el frente. Para terminar adujo que en España los trabajadores estaban indefensos, por lo que hubiera sido una locura lanzarlos contra el Estado. Ahora bien, nada de esto era óbice para que estuvieran preparando un movimiento definitivo, por lo que no podían distraer fuerzas antes de tiempo ${ }^{18}$.

La reflexión que podemos hacer es demasiado obvia, pues si el proletariado español era como lo valoraba Largo Caballero, si estaba inerme, si hacía poco los socialistas habían reconocido que no eran mayoría en ninguna región de España, y además avisaban una vez más al Gobierno públicamente de que se podían sublevar -las actas del Comité Nacional citado se publicaron-, todo conducía al absurdo. Absurdo que confirmaron los informes de las provincias sobre la preparación del movimiento revolucionario que estallaría en octubre: excepto en dos de ellas, en el resto no había nada.

En el momento en que tres miembros de la CEDA formaron parte del Gobierno, pareció que el orden constitucional saltaba por los aires, porque, con excepción de los radicales, los socialistas y todos los republicanos rompieron con la República, desde Azaña a Miguel Maura y Sánchez Román, pasando por la Esquerra. Los socialistas, como es de sobras conocido, salieron a la calle donde pudieron y cosecharon el fracaso que también conocemos, sin que sea este el lugar para hablar de Asturias y sus consecuencias para la convivencia dentro de la República.

Lo anterior no es óbice para observar que octubre de 1934 fue un escalón más en el desajuste interno de los socialistas, que acababan de fracasar en una aventura descabellada, a la que muchos de ellos fueron sabiendo que era un disparate. Ahora tocaba rescatar lo que se pudiera de la preeminencia política alcanzada en el primer bienio republicano. En la manera de cómo hacerlo se desarrolló el drama de la historia de los socialistas. De los socialistas y de la República misma, pues sin ellos los republicanos carecían de fuerzas para volver a gobernar. E igual les sucedía a los socialistas, conscientes de que sin los republicanos tampoco ellos gobernarían. En dilucidar de qué manera podía recomponerse esa alianza y si era necesario hacerlo se encierra el acto siguiente del drama socialista, y también republicano.

No viene al caso en la brevedad de estas páginas, hacer referencia a la política de los Gobiernos radical-cedistas ni a las causas de la disolución de las Cortes $^{19}$. A partir de ese momento, con unas elecciones en puertas, los socialistas tenían que decidir qué hacer.

18 Que el representante de los enseñantes fuera un izquierdista no sé si sería por cuestión de azar o por una carga genética del destino. Sea como sea, la discusión citada está en Boletín de la UGT, $\mathrm{n}^{\circ}$ 68, 8-1934.

19 Para esta cuestión remito a las modélicas investigaciones de M. Álvarez TARdio, "La CEDA y la democracia republicana», en la obra citada de F. DEL ReY, Palabras como puños, y El camino de la democracia en España: 1931 y 1978, Madrid, Gota a Gota, 2005. Va más allá y merece elogios el libro de M. Álvarez Tardio y R. Villa, El precio de la exclusión. La politica durante la Segunda República, Madrid, Encuentro, 2010. 
Prieto, seguido por quienes pasaron a denominarse centristas, no olvidaron que seguían siendo minoría en España. Por ello necesitaban rehacer la coalición con los republicanos para ir a las elecciones, si querían ganarlas. Coalición que, una vez que Martínez Barrio se escindió del Partido Radical, era notablemente parecida a la que proclamó la República en 1931. Ahora bien, como esa coalición volvía a ser esencialmente republicana con el objetivo, según proclamaban, de recuperar la República, los socialistas hubieron de presentar su responsabilidad de la revolución de Octubre como un movimiento de salvación del régimen y no como una revolución en sí.

Mas no todos los socialistas compartían este enfoque político. La que empezó a llamarse izquierda socialista, liderada por Largo Caballero, no quería saber nada de nuevas componendas con los republicanos, ésos que los habían defenestrado del poder en 1933. Para las Juventudes Socialistas, lideradas por Santiago Carrillo, la República y la democracia estaban muy bien como estaban, muertas y enterradas. Lo que tocaba ahora era transformar al PSOE en un partido genuinamente marxista y revolucionario que implantara la dictadura del proletariado. Para conseguirlo era necesario, primero, expulsar del partido a Besteiro y los suyos por reformistas; segundo, anular a los centristas de Prieto. Así el PSOE, dominado por la que se llamó Izquierda Socialista, se convertiría en «el Partido bolchevique de nuestro país».

En medio de esta historia vino a suceder otra que testimonia la importancia que venimos dando a las características del sujeto que historiamos ${ }^{20}$. Resultó que el Comité Nacional del PSOE se reunió en diciembre de 1935 para tratar la cuestión electoral. Largo Caballero, como presidente del partido, no puso reparos a ir en coalición con los republicanos, incluso a la redacción del programa común. Como también era secretario de la UGT, añadió que, como siempre, el sindicato iría con el PSOE a las elecciones y que a éste correspondía la dirección principal. Entonces, una cuestión reglamentaria que él pensaba ganar y que perdió, puso todo patas arriba, porque en una reacción que era muy usual en él, dimitió como presidente del PSOE. Lo mismo había hecho poco antes de octubre de 1934, obligando al cónclave socialista a rectificar e incluso a borrar el acta que recogía su dimisión. Ahora no hubo vuelta atrás. Largo Caballero, seguido de los suyos, se fue de la ejecutiva, dejándola en manos de los de Prieto y al PSOE sin presidente ${ }^{21}$.

Esto era un paso más en el descoyuntamiento de los socialistas, porque los centristas de Prieto controlaban la ejecutiva sin tener la mayoría en el partido ${ }^{22}$. Tanto, que al hacer las listas electorales varios miembros de ella no encontraron una agrupación socialista que los propusiera como candidatos. Por su parte, la izquierda socialista no podía dirigir la política del PSOE porque se había ido de los órganos que la decidían, pero sí podía bloquearla desde las organizaciones de base, en las que dominaba. Por ello, atrincherada en la UGT, convirtió al sindicato en un poder político que desafiaba al PSOE. Por si faltara algo, las Juventudes Socialistas, firmemente caballeristas, no se cansaban de predicar la revolución contra la República y la democracia burguesa, enalteciendo al Lenin español, a Largo Caballero.

Lo que no podía soslayar tal desbarajuste era que había elecciones. La ejecutiva del PSOE estaba negociando un pacto con los republicanos, al que los caballeristas iban a ir rastras. A rastras porque, pese a estar renegando públicamente de los republicanos, no tenían nada que ofrecer como alternativa a una alianza con ellos. Sólo pudieron recurrir a

20 Reitero las disculpas al lector, porque lo que escribo a partir de ahora es una reproducción casi textual de $\mathrm{mi}$ «The Socialists and Revolution», citado en la nota segunda.

21 El Comité Nacional en Fundación Pablo Iglesias, "Comité Nacional», AH-24-1, "Actas», 17-2-1935.

22 La autoridad de Santos Juliá en este tema es conocida, por lo que es ocioso recordar sus publicaciones. 
la formación de un bloque obrero, que únicamente era capaz de minusvalorar la alianza con los republicanos al oponerle otra genuinamente obrera. Su alcance fue muy limitado, porque al no contar, por definición, con la CNT, se redujo a un pacto con el pequeño PCE, más la aparición de las Juventudes Socialistas y la UGT como sujetos políticos independientes. Por ello los caballeristas no tuvieron más remedio que aceptar el pacto electoral que acabaría llamándose Frente Popular, pero dejando claro lo que pretendía con él. El programa de la coalición fue de una moderación que sorprende. Los republicanos y los socialistas moderados quisieron evitar explícitamente los errores del primer bienio republicano, fundamentalmente el control sindical de la legislación social, conscientes de que era lo había acabado con la coalición republicano-socialista en 193323. A los caballeristas el acuerdo les importaba nada. Aceptaban la coalición porque era necesaria para ganar las elecciones, pero como los republicanos eran quienes habían traicionado a la clase obrera en 1933, ella no se sometería de nuevo a los intereses de la clase burguesa -los republicanos eran definidos con esa categoría analítica-. Como afirmación política, la izquierda socialista exigió que la UGT firmase el acuerdo electoral como si fuera un partido, e impuso una condición determinante para el futuro: como la clase obrera - es decir, la UGT junto con la izquierda socialista- no se contentaba con recuperar las conquistas del primer bienio, porque quería ir a la república socialista, ningún socialista podría formar parte de un Gobierno con los republicanos. Si esta condición no se respetaba, la clase obrera rompería con el Frente Popular. Por tanto, el Gobierno habría de ser exclusivamente de republicanos, para cuando se agotase, el poder cayera en manos de esa clase obrera.

El ajustadísimo resultado de las elecciones es conocido. También lo es el maremagno de agitaciones, asaltos y violencia sin cuento que se produjo a partir de febrero. La acción de las izquierdas obreras desbordó a los republicanos, tratados por ellas como enemigos en vez de como aliados. El desbarajuste socialista era imparable, con los prietistas haciendo una cosa desde la ejecutiva del PSOE, los eaballeristas haciendo otra desde la UGT, y las Juventudes Socialistas en vías de unirse a las comunistas para seguir anunciando la inminente revolución bolchevique. Lo peor era que nadie tenía potestad para poner un mínimo de orden interno en el socialismo. Así, cuando muchos socialistas se dirigieron a la ejecutiva para que controlase a los de las juventudes, se les contestó que no era posible porque éstas eran autónomas. Igual acaeció con la ejecutiva de la UGT al ser reclamada para que evitara las polémicas públicas con el PSOE, respondiendo que no tenía capacidad estatutaria para impedirlas.

Ese desbarajuste acarreaba muy graves consecuencias políticas. La izquierda socialista por medio de la UGT venía actuando como otro partido socialista. Tanto que propuso al PSOE que el control del cumplimiento del programa electoral no sólo correspondiese al partido y al grupo parlamentario, sino al sindicato como cabeza del bloque obrero que formaba con las juventudes y el PCE. Con esta propuesta los caballeristas querían tener el control para impedir cualquier amago del PSOE de volver a gobernar con los republicanos, porque eso sería volver a la denostada colaboración de clases. Como es lógico, el PSOE rechazó la propuesta y la calificó de inaudita, pues por primera vez en su historia la UGT queria mandar en el PSOE.

El sujeto histórico al que nos referíamos al inicio de estas páginas se había quebrado. La distinción entre «nuestras organizaciones obreras y socialistas» mostraba ser tan real,

23 Las actas de la negociación del acuerdo electoral en Fundación Pablo Iglesias, AH 25-29, «Documentación CN del Frente Popular». 
que tenía descompuesto al socialismo español en unos momentos críticos para él y para la República.

Cuando hubo que nombrar compromisarios para elegir al presidente de la República, la UGT se negó a firmar el manifiesto del PSOE porque ella no había participado en ese nombramiento de compromisario hecho por el partido. Lo de menos para nuestro tema es que al final todos votaran a Azaña, porque la izquierda socialista recordó que ello no podía dar paso a la formación de un gobierno de coalición con participación de Prieto. No podía ser porque la UGT, la organización más fuerte del Frente Popular, como recalcaron, estaba en el Frente Popular bajo la condición de que ningún socialista formara parte del Gobierno. Si se incumplía esa condición, la UGT consideraría roto su compromiso con el Frente Popular y actuaría conforme a los intereses de la clase trabajadora.

La «clase obrera», es decir, la UGT y la izquierda socialista, actuaba como si el papel histórico de los republicanos estuviese a punto de concluir, como si la derecha hubiera dejado de existir, y como si el destino del Frente Popular fuese el de agotarse para dejarle el poder a ella, así, por las buenas. Esto era pura vaciedad política. Impedir que el Gobierno se fortaleciese con la entrada de Prieto en él, para dejarlo que se agotara era optar por la simpleza de la inacción. Más aún en unos momentos en que la República demandaba de los socialistas una política activa, la que fuese, pero nunca la simple espera. Para salir de esta parálisis los socialistas no pudieron hacer otra cosa que recurrir a los mecanismos estatutarios y convocar un congreso. Esperándolo les cogió el inicio de la guerra.

Entre tanto, quienes controlaban la ejecutiva del PSOE estaban desesperados por la irresponsabilidad de la izquierda socialista. Le dijeron a ésta una y otra vez que el momento en Europa no era el de la lucha entre capitalismo y socialismo, sino entre fascismo y democracia. Por eso se había formado el Frente Popular. Además, no había que confundir el verbalismo revolucionario con la revolución, porque ese camino sólo conducía a la contrarrevolución. Prieto afirmó en Bilbao el 25 de mayo que el fascismo estaba creciendo merced al desorden, y que la burguesía estaba en tal estado de miedo que podía ir a buscar al hombre providencial que asegurase un mínimo de vida civilizada en España. El mismo día, en Cádiz, Largo Caballero dijo lo contrario: la clase obrera estaba luchando contra la capitalista; la UGT no quería la actual República burguesa, y si la mantenía era para ir emancipando a los trabajadores; lo principal era constituir una alianza entre la UGT, la CNT y el PCE para que no pudieran vencerlos ni sus enemigos ni «las fuerzas coercitivas del Estado» ${ }^{24}$.

El 31 de mayo, los socialistas organizaron un mitin en Écija, en el que intervendrían Prieto y dos diputados asturianos líderes de la revolución de Octubre. Las Juventudes Socialistas Unificadas sevillanas - unificadas porque ya se habían fusionado con las comunistas- fueron a la ciudad astigitana para boicotear el acto. Así lo hicieron, y al comenzar el acto sus vítores a Largo Caballero y a la revolución proletaria impidieron hablar a los oradores. En medio de una monumental bronca, uno de los asistentes disparó su pistola. Prieto y sus acompañantes hubieron de escapar en un coche de la policía entre los tiros de los jóvenes socialistas.

Si el hecho en sí era gravísimo, más gravedad política, si cabe, revistió la reacción de la ejecutiva de la UGT. Cuando un miembro de ella pidió que condenara el atentado contra unos compañeros, los demás miembros de la misma, con Largo Caballero a la cabeza, se 
negaron a hacerlo, con el argumento de que los oradores habían sido los provocadores por ir contra la línea política de la UGT ${ }^{25}$.

Cuando fue asesinado Calvo Sotelo la ejecutiva de la UGT estaba en el extranjero. Un miembro de ella, que seguía en Madrid, dada la gravedad del momento firmó un manifiesto con el PSOE, las JJSS y el PCE. Al regresar Largo Caballero desautorizó al firmante, con el argumento de que la UGT no podía tener relaciones con la dirección del PSOE, a la que consideraba ilegitima. El mismo día el PSOE convocó a una reunión a la UGT. Ésta pidió que la invitación se la mandaran por escrito; además, varios miembros de la ejecutiva se negaron ir a la reunión porque era con una ejecutiva «facciosa». Al final la UGT fue, pero como no admitía que un socialista gobernara con los republicanos, lo que se acordó fue defender a la República desde órganos exclusivamente obreros y armados ${ }^{26}$. Es decir, los obreros no se iban a integrar en el Estado para defenderlo, sino que constituirían una fuerza paralela al mismo. Eufemismo que ocultaba el deseo de dejar a ese Estado inerme para ver, si por fin, llegaba el ansiado momento en el que el poder cayera en manos de la clase trabajadora. Lo que no previeron es que cuando les llegó ese poder fue a causa de una sublevación militar más fuerte de lo que habían pensado. Tanto que acabó con «nuestras organizaciones obreras», «con las socialistas» y con la odiada República burguesa, merced, entre otras cosas, al descoyuntamiento del sujeto histórico al que al nos referimos en el inicio de estas páginas.

25 «La fraternidad socialista ha sido ensangrentada por una prole de cainitas», escribió El Socialista. La negativa a condenar el atentado, en Fundación Pablo Iglesias, «Actas CE-UGT», 4-6-1936.

26 Fundación Pablo Iglesias, «Actas CE-UGT», 16 y17-7-1936. 